\title{
BMJ Open Doctors' perception of support and the processes involved in complaints investigations and how these relate to welfare and defensive practice: a cross- sectional survey of the UK physicians
}

\author{
Tom Bourne, ${ }^{1,2,3}$ Bavo De Cock, ${ }^{3}$ Laure Wynants, ${ }^{3}$ Mike Peters, ${ }^{4}$ \\ Chantal Van Audenhove, ${ }^{5}$ Dirk Timmerman, ${ }^{2,3}$ Ben Van Calster, ${ }^{3}$ Maria Jalmbrant ${ }^{6}$
}

To cite: Bourne T, De Cock B, Wynants L, et al. Doctors' perception of support and the processes involved in complaints investigations and how these relate to welfare and defensive practice: a cross-sectional survey of the UK physicians. BMJ Open 2017;7:e017856. doi:10.1136/ bmjopen-2017-017856

- Prepublication history and additional material for this paper are available online. To view these files, please visit the journal online (http://dx.doi org/10.1136/bmjopen-2017017856).

Received 23 May 2017 Revised 20 0ctober 2017 Accepted 25 October 2017

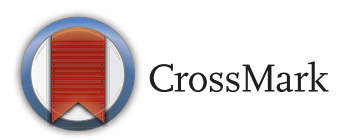

For numbered affiliations see end of article.

Correspondence to Professor Tom Bourne; tbourne@ic.ac.uk

\section{ABSTRACT}

Objective How adverse outcomes and complaints are managed may significantly impact on physician well-being and practice. We aimed to investigate how depression, anxiety and defensive medical practice are associated with doctors actual and perceived support, behaviour of colleagues and process issues regarding how complaints investigations are carried out.

Design A survey study. Respondents were classified into three groups: no complaint, recent/current complaint (within 6 months) or past complaint. Each group completed specific surveys.

Setting British Medical Association (BMA) members were invited to complete an online survey.

Participants 95636 members of the BMA were asked to participate. 7926 (8.3\%) completed the survey, of whom $1780(22.5 \%)$ had no complaint, 3889 (49.1\%) had a past complaint and 2257 (28.5\%) had a recent/current complaint. We excluded those with no complaints leaving 6144 in the final sample.

Primary outcomes measures We measured anxiety and depression using the Generalised Anxiety Disorder Scale 7 and Physical Health Questionnaire 9. Defensive practice was assessed using a new measure for avoidance and hedging.

Results Most felt supported by colleagues (61\%), only $31 \%$ felt supported by management. Not following process $(56 \%)$, protracted timescales $(78 \%)$, vexatious complaints (49\%), feeling bullied (39\%) or victimised for whistleblowing (20\%), and using complaints to undermine $(31 \%)$ were reported. Perceived support by management (relative risk (RR) depression: $0.77,95 \% \mathrm{Cl} 0.71$ to 0.83 ; RR anxiety: $0.80,95 \% \mathrm{Cl} 0.74$ to 0.87 ), speaking to colleagues (RR depression: $0.64,95 \% \mathrm{Cl} 0.48$ to 0.84 and RR anxiety: $0.69,95 \% \mathrm{Cl} 0.51$ to 0.94 , respectively), fair/ accurate documentation (RR depression: $0.80,95 \% \mathrm{Cl}$ 0.75 to 0.86 ; RR anxiety: $0.81,95 \% \mathrm{Cl} 0.75$ to 0.87 ), and being informed about rights (RR depression 0.96 (0.89 to 1.03 ) and anxiety 0.94 (0.87 to 1.02 ), correlated positively with well-being and reduced defensive practice. Doctors worried most about professional humiliation following a complaint investigation (80\%).

Conclusion Poor process, prolonged timescales and vexatious use of complaints systems are associated with

\section{Strengths and limitations of this study}

- A large number of physicians responded (10 930) and 6144 who had experienced a complaint completed the survey.

- Aspects of mental distress have been documented using validated questionnaires.

- We guaranteed to doctors filling in the survey that their responses were anonymous and untraceable; as a result, we feel respondents would have been more likely to be honest and open with their opinions.

- As we asked about past complaints, recall bias should be considered when interpreting the responses.

- The overall response rate of $11.4 \%$ means that ascertainment bias must be considered when looking at the results, although it should also be borne in mind that those most affected by a complaints process may have avoided taking part in the survey and doctors who have changed profession or been erased from the register would not have been included in the survey.

decreased psychological welfare and increased defensive practice. In contrast, perceived support from colleagues and management is associated with a reduction in these effects.

\section{INTRODUCTION}

We have previously reported on the impact of complaints procedures on the welfare, health and clinical practice of doctors in the UK. ${ }^{1}$ In this cross-sectional survey study, we used validated questionnaires to show doctors who had received a recent complaint were twice as likely to report suicidal thoughts, $77 \%$ more likely to suffer moderate-to-severe depression and had twice the risk of moderate-to-severe anxiety compared with those with no history of a complaint. The association was 
strongest when a complaint involved a referral to the UK regulator (the General Medical Council (GMC)). Doctors with a recent or current complaint also reported increased sleep difficulties, anger and irritability and relationship problems. We further found that $80 \%$ of doctors who responded to the survey practised medicine more defensively following complaints against themselves or colleagues. This involved 'hedging', which includes performing more tests than necessary, over-referral and overprescribing as well as 'avoidance', which includes avoiding procedures, not accepting high-risk patients or abandoning procedures early. We have also reported qualitative data on doctor's experiences of complaints. ${ }^{2}$ Physicians described feeling emotionally distressed; powerless, fearful of the consequences, unsupported and that their complaint was unfair. They reported that significant stressors were the unpredictability and prolonged duration of procedures, incompetence and poor communication by managers and a feeling that processes are biased in favour of complainants. Many said they practised defensively, limited their practice or changed career after a complaint. Very few physicians reported positive outcomes from complaints investigations.

In December 2015, Verhoef et $a \hat{l}$ carried out a semi-structured interview study on the impact of disciplinary processes on doctors in the Netherlands. They found that disciplinary processes can have a profound psychological and professional impact and that the time taken to carry out an investigation was a main contributing factor. In a study published in the British Medical Journal, Jain and Ogden ${ }^{4}$ described the impact of patient complaints on general practitioners (GPs) in the UK and reported an association with anger, depression and suicide. It is important to note that they also described clinicians involved in complaints practising medicine more defensively.

Others have also warned of the unintended consequences of regulation; McGivern and Fischer have argued that regulation is often focused on high-profile cases that promote the view that more regulation is required. ${ }^{5}$ This approach fails the 'invisible majority' of doctors who have never been accused of malpractice but who nevertheless become anxious about regulation and engage in defensive practice.

Recently Reisch et $a l,{ }^{6}$ in a survey of breast pathologists, reported that over $80 \%$ ordered additional tests in response to malpractice fears, recommended additional surgical sampling or asked for further opinions. The authors concluded that these defensive practices have important implications for healthcare costs and patient safety. The data of the study by Studdart $e t a l^{7}$ support these findings, they found that $93 \%$ of doctors practised defensively in high-liability environments, $43 \%$ of these ordered imaging when it was not necessary and $42 \%$ had restricted their practice in the previous 3 years to reduce their exposure to perceived risk.

Litigation, complaints and investigations are part of the processes that are designed to protect patients and maintain appropriate clinical standards. However, the burden and stress associated with these processes are clearly having unintended consequences and it may be argued that when examined as a whole, these structures may be causing more harm to patient care than good. While the regulatory system may protect patients from the misconduct of a relatively small number of doctors, it has a perverse effect on the majority of doctors who become preoccupied by defensive practice.

In our previous paper on the impact of complaints on doctors, we reported on the association between complaints procedures and doctor's well-being. ${ }^{1}$ We did not examine what aspects of the complaints processes or the behaviour of colleagues impacts either positively or negatively on doctor's well-being and health. This would be of interest as this information could then be used to amend processes to make them less damaging.

In this paper, we investigate whether depression, anxiety and defensive medical practice is associated with the support that is sought by doctors during complaints processes, their perceived support, the behaviour of colleagues as well as factors relating to complaints processes. Our expectation was that support from management and colleagues would ameliorate the impact of complaints processes. Conversely, we expected examples of poor process and behaviour would be associated with a negative effect of doctor's well-being and increase defensive practice.

\section{METHODS}

\section{Design and participants}

The British Medical Association (BMA) is the trade union and professional body representing 170000 doctors in the UK. Membership is voluntary. In November 2012, we invited 95636 members of the BMA, who had previously consented to take part in research to participate in the study. We sent them an email containing an information sheet describing the study and a link to an encrypted online questionnaire using Survey Monkey. We guaranteed to the participants that their responses would be both anonymous and untraceable, all consented to take part before starting the questionnaire.

The survey was open for 2 weeks during which time three reminders were sent out. In total, 10930 (11.4\%) doctors responded. Of those, we excluded 696 (6.4\%) because they completed the demographics section only, and $121(1.1 \%)$ as a technical error led to them being given incorrect sections to fill in. In total, $7926(72.5 \%)$ doctors completed the survey, of whom 1380 did not fill in some sections but we included them in the full analysis. Of the 7926 participants, $1780(22.5 \%)$ had no complaint, $3889(49.1 \%)$ had a past complaint and 2257 (28.5\%) had a recent/current complaint. Participants with no complaints were excluded from this analysis relating to the experience of complaints processes as well as participants who did not answer any of the questions on the process, leaving us with 6144 participants in the 
final sample, of which $63 \%$ had a past complaint and $37 \%$ had a recent or current complaint. We compared our study population to the characteristics of the entire BMA database to see if our cohort of members was representative. We found our population was similar in relation to gender, but slightly older with more consultants and GPs and fewer from ethnic minorities compared with the BMA database. Details of this comparison can be found in table 1.

The different types of complaint or investigation that were considered in the study are described below and the breakdown of the number of each complaint type is listed in table 2. We asked doctors to complete the survey based on the complaint they perceived had the most impact on them (in case there was overlap between different complaints procedures).

Informal (21\%): this involves the complainant talking directly to the individual concerned about their complaint. If not resolved locally it can be escalated.

Formal $(50 \%)$ : this is a written complaint, most often to the chief executive or an organisation that required an investigation to be carried out and a written response given. The outcome may be that disciplinary action or referral to the GMC by an employer ensues.

Serious untoward incident (SUI) (12\%): an SUI generally relates to a poor clinical outcome, unexpected death or threat to public health. However, it may also occur if an event may damage the reputation or lead to a lack of confidence in a service. Such an investigation must be both commissioned and undertaken independently of the care that the investigation is considering. Again the outcome may lead to a recommendation for disciplinary action or referral to the regulator (the GMC).

GMC (14\%): a complaint about a doctor can be made to the GMC for concerns about his or her clinical practice, and his or her personal behaviour. The GMC can suspend doctors from work while they investigate them, issue warnings and undertakings, restrict a doctor's practice or make them work under supervision, suspend them or permanently strike them off the medical register and prevent them from working.

\section{The survey}

We used a cross-sectional survey design where participants were streamed into three groups: current/ recent complaint (ongoing or resolved within the last 6 months), past complaint (resolved $>6$ months ago) and no complaints (not included in this analysis). Each group completed a slightly different version of the questionnaire. Participants in the current complaints and no complaints group were asked about their current mood and health, whereas the past complaints group were also asked to respond about their mood and health at the time of the complaint. We trialled the questions on process on 20 doctors of different grade and specialty and incorporated their feedback into the questionnaire design. We have included the questionnaire as supplementary online information (see online supplementary file 1). Further information on the questionnaire can be found in the study by Bourne et al. ${ }^{1}$ We estimate that the time required to fill in the entire questionnaire was $30 \mathrm{~min}$.

\section{MEASURES}

\section{Complaints exposure and process}

We asked physicians 75 questions about their complaint(s), whether it had occurred in the past or was current. We generated the questions from the pilot study and also from Bark et al. ${ }^{8}$ These included why the complaint had occurred, who made it, how long the process went on for, the outcome as well as support sought and obtained. While the majority of the questions used a 5-point scale, some questions were qualitative and a few were yes/no.

\section{Support sought by doctors during complaints processes}

Eight questions were asked about what support was sought by doctors during the complaints process. Each question related to support from a different source and an option was given to answer yes or no.

\section{PERCEIVED SUPPORT}

Agreement with 15 statements on perceived support was measured using a 5-point scale from 'strongly agreed' to 'strongly disagreed'. Respondents were also able to mark the questions on perceived support as 'not applicable'.

\section{Worrying about outcome}

Seven possible outcomes were listed in the survey and doctors were asked to what extent they were worried about them ranging on a 5-point scale from 'not at all' to 'a lot'.

\section{Factors relating to complaints processes and behaviour of colleagues}

Issues about the process followed and colleagues' behaviour in relation to the complaint were assessed using 11 statements. The doctor was asked to what extent these applied on a 5-point scale from 'not at all' to 'definitely'.

\section{Depression and anxiety}

Current depression was assessed using the Physical Health Questionnaire (PHQ-9).${ }^{9}{ }^{10}$ Respondents with a score $\geq 10$ were considered depressed. We used the Generalised Anxiety Disorder Scale (GAD-7) ${ }^{11}$ to assess current anxiety, and respondents were considered to be anxious if they had a score $\geq 10$. Both are well validated and standardised measures of symptom severity of depression and anxiety, respectively.

\section{Defensive medical practice}

Following a review of the literature, we developed 20 items to measure defensive medical practice. ${ }^{61213}$ Twelve further items were developed from the pilot study. These were rated either with a yes/no response or on a 5-point scale. After carrying out an exploratory factor analysis, two underlying factors were identified. The first related 
Table 1 Demographic information for the study population compared with the total British Medical Association membership consented for research

\section{Total British \\ Medical \\ Association \\ membership \\ consented for Study population research (\%) $\quad \mathbf{n}(\%)$}

\begin{tabular}{|ccc|}
\hline Age (years) & \multicolumn{1}{c}{-} & \multicolumn{1}{c}{-} \\
\hline up to 25 & $17.8 \%$ & $15(0.2 \%)$ \\
\hline 26 to 29 & $9.0 \%$ & $164(2.7 \%)$ \\
\hline 30 to 34 & $9.6 \%$ & $398(6.5 \%)$ \\
\hline 35 to 39 & $10.3 \%$ & $643(10.5 \%)$ \\
\hline 40 to 44 & $10.3 \%$ & $837(13.7 \%)$ \\
\hline 45 to 49 & $10.8 \%$ & $1105(18.1 \%)$ \\
\hline 50 to 54 & $10.3 \%$ & $1262(20.7 \%)$ \\
\hline 55 to 59 & $8.1 \%$ & $1013(16.6 \%)$ \\
\hline 60 to 64 & $5.0 \%$ & $429(7 \%)$ \\
\hline 65 to 69 & $3.0 \%$ & $178(2.9 \%)$ \\
\hline over 69 & $5.9 \%$ & $63(1 \%)$ \\
\hline Gender & $46.3 \%$ Female & $2800(46.5 \%)$ Female \\
\hline
\end{tabular}

Place of

qualification

\begin{tabular}{|ccc}
\hline UK & $80.1 \%$ & $5077(82.6 \%)$ \\
\hline India & $8.2 \%$ & $331(5.4 \%)$ \\
\hline Pakistan & $2.2 \%$ & $55(0.9 \%)$ \\
\hline Ireland & $0.9 \%$ & $90(1.5 \%)$ \\
\hline Nigeria & $1.1 \%$ & $64(1 \%)$ \\
\hline Germany & $0.7 \%$ & $79(1.3 \%)$ \\
\hline South Africa & $0.7 \%$ & $58(0.9 \%)$ \\
\hline Other & $6.2 \%$ & $390(6.3 \%)$ \\
\hline Ethnicity & - & - \\
\hline White British & $67.6 \%$ & $4825(80.5 \%)$ \\
\hline Asian or Asian & $23.3 \%$ & \\
British & & $849(14.2 \%)$ \\
\hline Black or Black & $3.5 \%$ & $122(2 \%)$ \\
British & & $69(1.2 \%)$ \\
\hline Chinese or & $2.9 \%$ & $127(2.1 \%)$ \\
Chinese British & & - \\
\hline Mixed & $2.7 \%$ & $66(1.1 \%)$ \\
\hline Grade & - & $2301(37.5 \%)$ \\
\hline Academics & $2.1 \%$ & $2643(43 \%)$ \\
\hline Consultants & $27.2 \%$ & $568(9.2 \%)$ \\
\hline General practice & $26.0 \%$ & $313(5.1 \%)$ \\
\hline Junior doctors & $26.4 \%$ & $54(0.9 \%)$ \\
\hline SASC & $5.3 \%$ & $199(3.2 \%)$ \\
\hline Retired & $8.6 \%$ & \\
\hline Other or no & $4.4 \%$ & \\
answer & & \\
\hline
\end{tabular}

Continued
Table 1 Continued

Total British

Medical

Association

membership

consented for Study population

research (\%) $n(\%)$

\begin{tabular}{llc}
\hline $\begin{array}{l}\text { Specialty* } \\
\text { Accident and } \\
\text { emergency }\end{array}$ & / & - \\
Anaesthetics & / & $341(2.3 \%)$ \\
General medicine & / & $690(11.4 \%)$ \\
General practice & / & $2845(47.2 \%)$ \\
Obstetrics and & / & $62(1 \%)$ \\
gynaecology & & $111(1.8 \%)$ \\
Oncology & $/$ & $271(4.5 \%)$ \\
Other & $/$ & $66(1.1 \%)$ \\
Paediatrics & $/$ & $495(8.2 \%)$ \\
Pathology & $/$ & $106(1.8 \%)$ \\
Psychiatry & / & $604(10 \%)$ \\
Radiology & $/$ &
\end{tabular}

*No data were available on the distribution of specialty in the BMA population.

SASC, Staff, Associate Specialists and Specialty doctors.

to carrying out too many investigations and being over cautious regarding the management of patients-we called this 'hedging' and was measured on a scale from 0 to 36 (9 items, eg, 'carried out more tests than necessary', 'referred patient for second opinion more than necessary' and 'admitted patients to the hospital when the patient could have been discharged home safely or managed as an outpatient', Cronbach's $\alpha=0.92)$. The second factor we called 'avoidance' as it related to avoiding some areas of practice, this was measured on a scale from 0 to 12 (3 items, 'stopped doing aspects of my job', 'not accepting high-risk patients in order to avoid possible complications' and 'avoiding a particular type of invasive procedure', Cronbach's $\alpha=0.77$ ).

Avoidance was dichotomised as never displaying avoidance behaviour and displaying at least some avoidance

Table 2 The number and percentage of the type of complaint reported in the study.

\begin{tabular}{lc}
\hline Type of complaint investigation* & $\mathbf{n}(\%)$ \\
\hline General Medical Council & $873(14.2 \%)$ \\
Serious untoward incident & $732(11.9 \%)$ \\
Formal & $3096(50.4 \%)$ \\
Informal & $1284(20.9 \%)$ \\
Missing & $159(2.6 \%)$ \\
Total & $6144(100 \%)$
\end{tabular}

${ }^{*}$ Doctors were asked to fill in the questionnaire based on the complaint/investigation that had most impact on them. 
behaviour. Approximately half of the respondents (54\%) never displayed avoidance behaviour. There were few respondents (16\%) that never displayed hedging behaviour, therefore, we decided to use a median split to dichotomise hedging. A score below the median $(<10)$ would then indicate that the respondent never or seldom engaged in hedging, while a score above the median $(\geq 10)$ would indicate that the respondent sometimes or often engaged in hedging behaviour.

\section{Statistical analysis}

To analyse associations with defensive practice, only doctors with an ongoing/recent complaint $(n=2257)$ and doctors with a past complaint $(n=3887)$ were included. For the analysis on depression and anxiety, only doctors with an ongoing/recent complaint were included since there are too many confounding variables that could have influenced the current level of depression or anxiety of doctors with a past complaint.

The outcome variables (depression, anxiety, avoidance, hedging) were dichotomised as described above. To examine relationships with the outcome variables, a Poisson regression analysis with robust error variance was used to estimate relative risks (RRs). ${ }^{14}$ When using items of perceived support, we withheld the possible answer 'not applicable' from the analyses since this did not convey any information on levels of perceived support. RRs were visualised using forest plots. No significance testing was used, results were presented with $95 \%$ CIs to quantify the uncertainty. We assessed whether relationships varied with the type or timing of the complaint using interaction terms. We used the dependent false discovery rate procedure as a guide to explore potentially relevant interaction terms. ${ }^{15}$ The procedure was used once for type of complaint (116 interaction terms), and once for timing of complaint (58 interaction terms), both using a $5 \%$ alpha level.

As is typical in survey research, we observed item non-response. To be consistent with our previous analysis, ${ }^{1}$ missing data were addressed using multiple stochastic imputation (MI). Using this approach, missing values were replaced by 100 plausible values leading to 100 completed datasets. Replacing missing values multiple times represents the uncertainty about the imputed values (see online supplementary file 2).

A sensitivity analysis was then performed to assess the impact of item non-response by comparing the results of complete case analysis to results after MI, which assumes 'missingness at random'. In addition, a second MI analysis was performed assuming 'missingness not at random' for the outcome variables because these are based on sensitive questions. It is plausible respondents with missing data might have been more anxious or depressed, or more likely to display hedging or avoidance (see online supplementary file 2). Results for the complete case analysis for MI based on missingness at random and for MI based on missingness not at random were similar, hence we only report results for standard MI (assuming missingness at random). SAS was used for the data analysis (V.9.4, SAS Institute, Cary, North Carolina, USA). MIs were performed using the mice package ${ }^{16}$ in $\mathrm{R}^{17}$

\section{RESULTS}

\section{Descriptive statistics}

Detailed information on the descriptive statistics of items assessing different aspects of actual support, perceived support, process-related issues and worry about the consequences of a complaint are seen in table 3. Most physicians discussed their complaint with family, friends or colleagues.

Perceived support: the majority (61\%) felt supported by their colleagues, whereas only $31 \%$ reported they felt supported by management.

Process issues: $56 \%$ said normal process was not followed. For example, $78 \%$ indicated that the timescale was needlessly protracted, $27 \%$ did not feel they were informed about representation and $17 \%$ thought the documentary record was not fair and accurate.

Behaviour: $20 \%$ felt victimised for being a whistleblower and 39\% reported being bullied during the investigation. Inappropriate or vexatious abuse of the complaints system was reported by $49 \%$ of physicians, $32 \%$ felt managers used a complaint to undermine them and $24 \%$ reported colleagues used a complaint to take advantage either financially or professionally.

Most respondents worried about the consequences of the complaint. The most common concerns were professional or public humiliation ( $80 \%$ and $70 \%$, respectively) and having a marked record in the future $(78 \%)$.

\section{Psychological welfare and health}

The RRs for associations with depression and anxiety are presented in table 3 and figure 1 .

\section{Actual and perceived support}

Depression and anxiety were more common among doctors who reported speaking to family or friends about their complaint (RR depression: $1.46,95 \%$ CI 1.06 to 2.02; RR anxiety: $1.58,95 \%$ CI 1.11 to 2.26 ), when they engaged independent legal advice (RR depression: $1.85,95 \%$ CI 1.45 to 2.36 ; RR anxiety: $1.70,95 \%$ CI 1.29 to 2.23), accessed support from the BMA employment advice service (RR depression: 2.06, 95\% CI 1.68 to 2.52; RR anxiety: $1.71,95 \%$ CI 1.35 to 2.17 ) or BMA counselling service (RR depression: 1.91, 95\% CI 1.50 to 2.44; RR anxiety: 1.74, 95\% CI 1.33 to 2.29 ). The risk ratios for both depression and anxiety were lowest when doctors reported they had spoken to their colleagues (RR: $0.64,95 \%$ CI 0.48 to 0.84 and RR: $0.69,95 \%$ CI 0.51 to 0.94 , respectively).

Perceived support from management was associated with a less depression and anxiety (RR depression: 0.77 , 95\% CI 0.71 to 0.83 ; RR anxiety: $0.80,95 \%$ CI 0.74 to $0.87)$. The perception of support from medical professional organisations, and defence organisations also 
Table 3 Descriptive information for the items in the questionnaire used in the analysis

\begin{tabular}{|c|c|c|c|c|c|c|c|c|c|c|c|}
\hline \multicolumn{4}{|c|}{ Actual support } & Missing & \multicolumn{2}{|l|}{ No } & \multicolumn{5}{|c|}{ Yes } \\
\hline & 660 & \multicolumn{2}{|c|}{$786(14 \%)$} & $4698(86 \%)$ & - & - & - & - \\
\hline \multicolumn{4}{|c|}{ Spoke to colleagues about it } & 625 & \multicolumn{2}{|c|}{$406(7 \%)$} & $5113(93 \%)$ & - & - & - & - \\
\hline \multicolumn{4}{|c|}{$\begin{array}{l}\text { Accessed support from medical professional support } \\
\text { organisation }\end{array}$} & 801 & \multicolumn{2}{|c|}{2177 (41\%) } & $3166(59 \%)$ & - & - & - & - \\
\hline \multicolumn{4}{|c|}{$\begin{array}{l}\text { Accessed support from BMA counselling/other support } \\
\text { organisation }\end{array}$} & 983 & \multicolumn{2}{|c|}{$4764(92 \%)$} & $397(8 \%)$ & - & - & - & - \\
\hline Perceived support & Missing & $\begin{array}{l}\text { Strongly } \\
\text { disagree }\end{array}$ & \multicolumn{2}{|c|}{ Disagree } & Neutral & Agree & \multicolumn{2}{|c|}{$\begin{array}{l}\text { Strongly } \\
\text { agree }\end{array}$} & \multicolumn{3}{|c|}{$\begin{array}{l}\text { Not } \\
\text { applicable }\end{array}$} \\
\hline $\begin{array}{l}\text { I felt supported by my } \\
\text { medical professional } \\
\text { organisation }\end{array}$ & 890 & 307 (6\%) & $260(5$ & $5 \%)$ & $946(18 \%)$ & $602(11 \%)$ & 588( & & 255 & $(49 \%$ & \\
\hline $\begin{array}{l}\text { I felt supported by my } \\
\text { defence organisation }\end{array}$ & 826 & $214(4 \%)$ & $221(4$ & 4\%) & $659(12 \%)$ & $1077(20 \%)$ & 1547 & & 160 & $(30 \%$ & \\
\hline
\end{tabular}

\begin{tabular}{|c|c|c|c|c|c|c|}
\hline Process-related issues & Missing & Not at all & A little & To some extent & Quite a lot & Definitely \\
\hline $\begin{array}{l}\text { Documentary record was fair and } \\
\text { accurate }\end{array}$ & 1703 & 749 (17\%) & $545(12 \%)$ & $1116(25 \%)$ & 1124 (25\%) & 907 (20\%) \\
\hline $\begin{array}{l}\text { Timescale was needlessly } \\
\text { protracted }\end{array}$ & 1316 & $1066(22 \%)$ & $737(15 \%)$ & $1006(21 \%)$ & $627(13 \%)$ & $1392(29 \%)$ \\
\hline $\begin{array}{l}\text { Inappropriate or vexatious use of } \\
\text { hospital clinical risk process }\end{array}$ & 1990 & 2098 (51\%) & $470(11 \%)$ & $626(15 \%)$ & $298(7 \%)$ & $662(16 \%)$ \\
\hline $\begin{array}{l}\text { Complaint was due to } \\
\text { dysfunctional team }\end{array}$ & 1559 & $2910(63 \%)$ & $323(7 \%)$ & $481(10 \%)$ & $267(6 \%)$ & $604(13 \%)$ \\
\hline $\begin{array}{l}\text { Felt victimised because I had } \\
\text { been a whistleblower }\end{array}$ & 1691 & $3552(80 \%)$ & $184(4 \%)$ & $190(4 \%)$ & $148(3 \%)$ & $379(9 \%)$ \\
\hline $\begin{array}{l}\text { I felt bullied during the } \\
\text { investigation }\end{array}$ & 1517 & $2842(61 \%)$ & $372(8 \%)$ & $502(11 \%)$ & $268(6 \%)$ & $643(14 \%)$ \\
\hline $\begin{array}{l}\text { Managers used complaints to } \\
\text { undermine my position }\end{array}$ & 1603 & $3117(69 \%)$ & $307(7 \%)$ & $333(7 \%)$ & $207(5 \%)$ & $577(13 \%)$ \\
\hline $\begin{array}{l}\text { Colleagues used process to } \\
\text { gain advantage financially or } \\
\text { professionally }\end{array}$ & 1561 & $3495(76 \%)$ & $233(5 \%)$ & 267 (6\%) & $149(3 \%)$ & $439(10 \%)$ \\
\hline
\end{tabular}

\begin{tabular}{|c|c|c|c|c|c|c|}
\hline Worries about the complaint & Missing & Not at all & A little & To some extent & Quite a lot & A lot \\
\hline I worried about loss of livelihood & 953 & $1889(36 \%)$ & $605(12 \%)$ & $1034(20 \%)$ & $380(7 \%)$ & $1283(25 \%)$ \\
\hline I worried about public humiliation & 951 & $1532(30 \%)$ & $593(11 \%)$ & $1164(22 \%)$ & $606(12 \%)$ & $1298(25 \%)$ \\
\hline $\begin{array}{l}\text { I worried about having aspects of } \\
\text { clinical practice restricted }\end{array}$ & 972 & $2296(44 \%)$ & $720(14 \%)$ & $810(16 \%)$ & $446(9 \%)$ & $900(17 \%)$ \\
\hline
\end{tabular}


Table 3 Continued

\begin{tabular}{|c|c|c|c|c|c|c|}
\hline Worries about the complaint & Missing & Not at all & A little & To some extent & Quite a lot & A lot \\
\hline I worried about family problems & 984 & 2738 (53\%) & $569(11 \%)$ & $704(14 \%)$ & $398(8 \%)$ & $751(15 \%)$ \\
\hline $\begin{array}{l}\text { I worried about having a marked } \\
\text { record in the future }\end{array}$ & 937 & $1105(21 \%)$ & $524(10 \%)$ & $1098(21 \%)$ & $746(14 \%)$ & $1734(33 \%)$ \\
\hline I worried about financial costs & 985 & $2227(43 \%)$ & $701(14 \%)$ & $894(17 \%)$ & $438(8 \%)$ & $899(18 \%)$ \\
\hline
\end{tabular}

BMA, British Medical Association.

related to lower rates of depression and anxiety (RRs depression: 0.84 for both items; RRs anxiety: 0.87 for both items).

Process-related issues: when the timescale for a complaints investigation was protracted, this was associated with greater anxiety and depression (RR: 1.16, 95\% CI 1.08 to 1.26 ; RR: $1.20,95 \%$ CI 1.12 to 1.29 , respectively). Perceiving that normal process was not being followed was also associated with increased anxiety (RR: 1.18, 95\% CI 1.10 to 1.26 ) and depression (RR: $1.15,95 \% \mathrm{CI}$ 1.08 to 1.23). Conversely feeling the documentary record was fair and accurate was related to less depression and anxiety (RR depression: $0.80,95 \%$ CI 0.75 to 0.86 ; RR anxiety: $0.81,95 \%$ CI 0.75 to 0.87 ).

Behavioural issues: feeling bullied, victimised as a whistleblower and perceiving colleagues or management were taking advantage of the situation were associated with higher rates of depression and anxiety (RRs 1.22-1.28 for depression and 1.22-1.30 for anxiety).

Worrying about the consequences of the complaint: the more doctors were worried about the consequences of the complaint, the higher the reported depression and anxiety (RRs: $1.38-1.53$ for depression and 1.33-1.52 for anxiety).

\section{Defensive practice}

The RRs for hedging and avoidance are presented in table 4 and figure 2. There were clear differences in results for hedging and avoidance.

\section{Actual and perceived support}

Hedging was greatest when doctors spoke to family or friends (RR: $1.28,95 \%$ CI 1.17 to 1.41 ), spoke to colleagues (RR: $1.23,95 \%$ CI 1.09 to 1.40 ) and when they accessed help from medical professional support organisations (RR: $1.22,95 \%$ CI 1.15 to 1.30 ). No clear relationships were found between perceived support and hedging. Generally, process-related issues were not strongly associated with hedging, although a protracted timescale for a complaints process was a factor (RR: 1.05, 95\% CI 1.03 to 1.07$)$.

Avoidance-related positively to most aspects of actual support (RRs: 1.01-1.25), but was lower when doctors perceived they were well supported by their management (RR: $0.91,95 \%$ CI 0.89 to 0.93 ) or colleagues (RR: 0.90, $95 \%$ CI 0.89 to 0.92$)$.
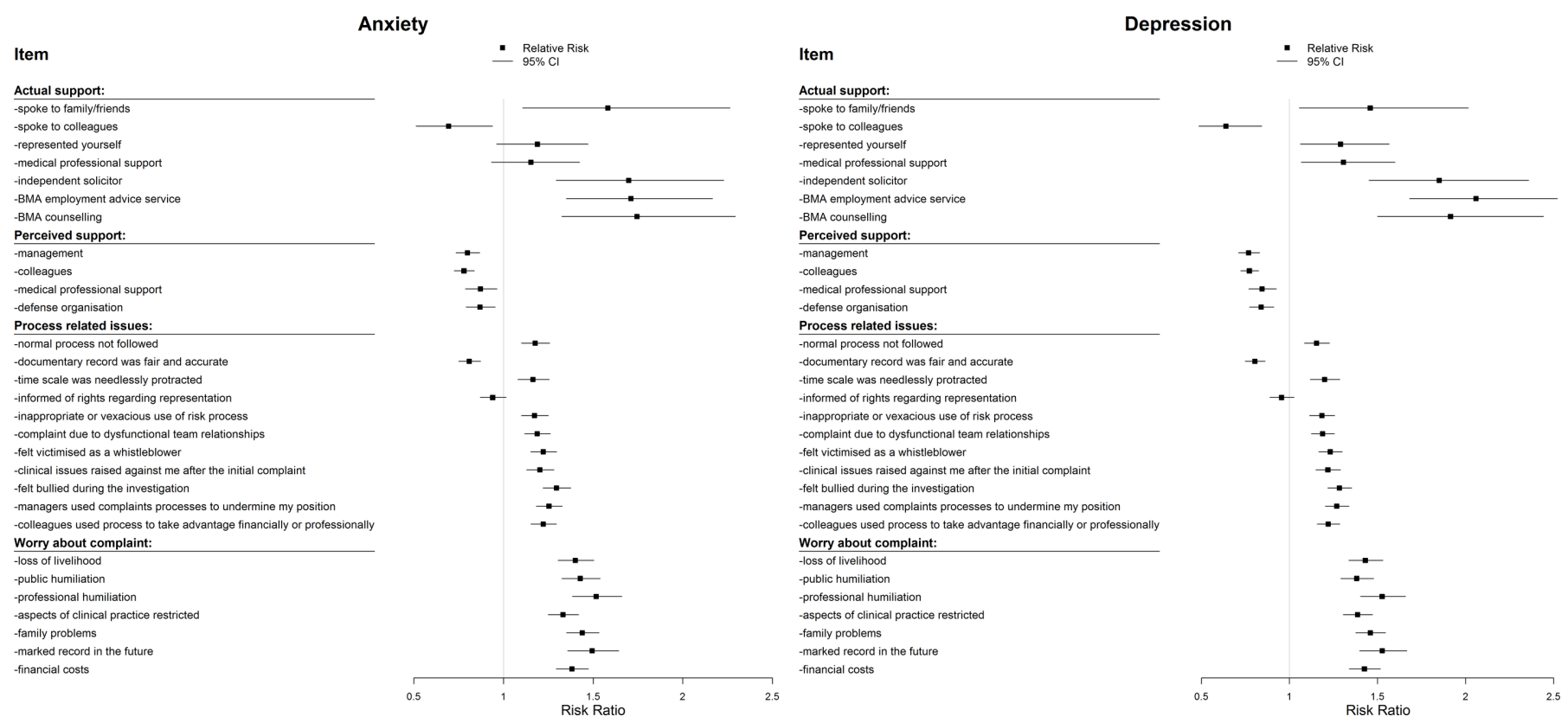

Figure 1 The relative risks (with 95\% Cls) for anxiety and depression in relation to actual and perceived support as well as process-related issues. 
Table 4 Relative risks for anxiety, depression, hedging and avoidance behaviour in relation to perceived and actual support, colleagues' behaviour as well as process-related issues

\begin{tabular}{|c|c|c|c|c|}
\hline \multirow[b]{2}{*}{ Item } & \multicolumn{4}{|c|}{ Relative risks $(95 \% \mathrm{Cl})$} \\
\hline & Anxiety & Depression & Hedging & Avoidance \\
\hline Actual support & - & - & - & - \\
\hline Spoke to family/friends & 1.58 (1.11 to 2.26$)$ & 1.46 (1.06 to 2.02$)$ & $1.28(1.17$ to 1.41$)$ & $1.15(1.05-1.27)$ \\
\hline Spoke to colleagues & 0.69 (0.51 to 0.94$)$ & 0.64 (0.48 to 0.84$)$ & $1.23(1.09$ to 1.40$)$ & $1.01(0.90-1.13)$ \\
\hline Represented yourself & 1.19 (0.96 to 1.47$)$ & 1.29 (1.06 to 1.57$)$ & 0.99 (0.93 to 1.05$)$ & $1.07(1.01-1.15)$ \\
\hline Medical professional support & 1.15 (0.93 to 1.42$)$ & 1.31 (1.07 to 1.60$)$ & $1.22(1.15$ to 1.30$)$ & $1.19(1.12-1.27)$ \\
\hline Independent solicitor & 1.70 (1.29 to 2.23$)$ & 1.85 (1.45 to 2.36$)$ & 0.98 (0.89 to 1.09$)$ & $1.19(1.08-1.30)$ \\
\hline BMA employment advice service & 1.71 (1.35 to 2.17$)$ & 2.06 (1.68 to 2.52$)$ & 0.81 (0.74 to 0.90$)$ & $1.24(1.14-1.34)$ \\
\hline BMA counselling & 1.74 (1.33 to 2.29$)$ & 1.91 (1.50 to 2.44$)$ & 0.96 (0.86 to 1.07$)$ & $1.25(1.14-1.38)$ \\
\hline Perceived support from & - & - & - & - \\
\hline Management & 0.80 (0.74 to 0.87$)$ & 0.77 (0.71 to 0.83$)$ & 0.98 (0.96 to 1.00$)$ & $0.91(0.89-0.93)$ \\
\hline Colleagues & 0.78 (0.73 to 0.84$)$ & 0.77 (0.72 to 0.83$)$ & 0.96 (0.94 to 0.98$)$ & $0.90(0.89-0.92)$ \\
\hline Medical professional support & 0.87 (0.79 to 0.96$)$ & 0.84 (0.77 to 0.93$)$ & 0.98 (0.95 to 1.01$)$ & $0.98(0.95-1.01)$ \\
\hline Defence organisation & 0.87 (0.79 to 0.95$)$ & 0.84 (0.77 to 0.91$)$ & 1.03 (1.00 to 1.06$)$ & $0.96(0.93-0.99)$ \\
\hline Process-related issues* & - & - & - & - \\
\hline Normal process not followed & 1.18 (1.10 to 1.26$)$ & 1.15 (1.08 to 1.23$)$ & 1.01 (0.99 to 1.03$)$ & $1.07(1.05-1.09)$ \\
\hline $\begin{array}{l}\text { Documentary record was fair and } \\
\text { accurate }\end{array}$ & 0.81 (0.75 to 0.87$)$ & $0.80(0.75$ to 0.86$)$ & 0.98 (0.96 to 1.00$)$ & $0.94(0.92-0.96)$ \\
\hline Timescale was needlessly protracted & $1.16(1.08$ to 1.26$)$ & 1.20 (1.12 to 1.29$)$ & 1.05 (1.03 to 1.07$)$ & $1.10(1.07-1.12)$ \\
\hline $\begin{array}{l}\text { Informed of rights regarding } \\
\text { representation }\end{array}$ & 0.94 (0.87 to 1.02$)$ & 0.96 (0.89 to 1.03$)$ & 0.97 (0.95 to 0.99$)$ & $0.96(0.94-0.98)$ \\
\hline $\begin{array}{l}\text { Inappropriate or vexatious use of risk } \\
\text { process }\end{array}$ & 1.17 (1.10 to 1.25$)$ & 1.18 (1.11 to 1.26$)$ & $1.02(1.00$ to 1.04$)$ & $1.10(1.08-1.12)$ \\
\hline $\begin{array}{l}\text { Complaint due to dysfunctional team } \\
\text { relationships }\end{array}$ & $1.19(1.12$ to 1.26$)$ & 1.19 (1.12 to 1.25$)$ & 0.99 (0.97 to 1.01$)$ & $1.08(1.06-1.10)$ \\
\hline Felt victimised as a whistleblower & $1.22(1.15$ to 1.30$)$ & $1.23(1.17$ to 1.30$)$ & 0.99 (0.97 to 1.01$)$ & $1.09(1.07-1.11)$ \\
\hline $\begin{array}{l}\text { Clinical issues raised against me after } \\
\text { the initial complaint }\end{array}$ & 1.20 (1.13 to 1.28$)$ & 1.22 (1.15 to 1.29$)$ & 1.04 (1.01 to 1.06$)$ & $1.11(1.08-1.13)$ \\
\hline Felt bullied during the investigation & 1.30 (1.22 to 1.38$)$ & 1.28 (1.22 to 1.35$)$ & 1.03 (1.01 to 1.05$)$ & $1.11(1.09-1.13)$ \\
\hline $\begin{array}{l}\text { Managers used complaints processes } \\
\text { to undermine my position }\end{array}$ & 1.25 (1.18 to 1.33$)$ & 1.27 (1.20 to 1.34$)$ & 1.01 (0.99 to 1.03$)$ & $1.11(1.09-1.13)$ \\
\hline $\begin{array}{l}\text { Colleagues used process to take } \\
\text { advantage financially or professionally }\end{array}$ & $1.22(1.15$ to 1.30$)$ & 1.22 (1.16 to 1.29$)$ & $1.02(1.00$ to 1.04$)$ & $1.11(1.09-1.14)$ \\
\hline Worrying about the complaint & - & - & - & - \\
\hline Loss of livelihood & 1.40 (1.30 to 1.50$)$ & 1.43 (1.34 to 1.53$)$ & 1.11 (1.09 to 1.13$)$ & $1.14(1.12-1.16)$ \\
\hline Public humiliation & 1.43 (1.33 to 1.54$)$ & $1.38(1.29$ to 1.48$)$ & $1.13(1.12$ to 1.15$)$ & $1.15(1.12-1.17)$ \\
\hline Professional humiliation & 1.52 (1.38 to 1.66$)$ & 1.53 (1.40 to 1.66$)$ & 1.14 (1.12 to 1.16$)$ & $1.15(1.13-1.18)$ \\
\hline Aspects of clinical practice restricted & 1.33 (1.25 to 1.42$)$ & 1.39 (1.31 to 1.47$)$ & $1.10(1.08$ to 1.12$)$ & $1.14(1.11-1.16)$ \\
\hline Family problems & 1.44 (1.35 to 1.53$)$ & $1.46(1.38$ to 1.55$)$ & 1.11 (1.09 to 1.13$)$ & $1.14(1.12-1.16)$ \\
\hline Marked record in the future & 1.49 (1.36 to 1.64$)$ & 1.53 (1.40 to 1.67$)$ & 1.13 (1.11 to 1.16$)$ & $1.14(1.11-1.16)$ \\
\hline Financial costs & 1.38 (1.29 to 1.47$)$ & 1.43 (1.34 to 1.52$)$ & 1.11 (1.09 to 1.13$)$ & $1.15(1.13-1.17)$ \\
\hline
\end{tabular}

*Items have been paraphrased from the original questionnaire. The full questionnaire can be found in online supplementary file 1

Process-related issues and worrying about the consequences of the complaint

While process-related issues were not strongly related to hedging, avoidance behaviour (eg, abandoning procedures early) was more common when negative process or behavioural issues were reported (RR: 1.071.11). Conversely, positive process issues (eg, being 

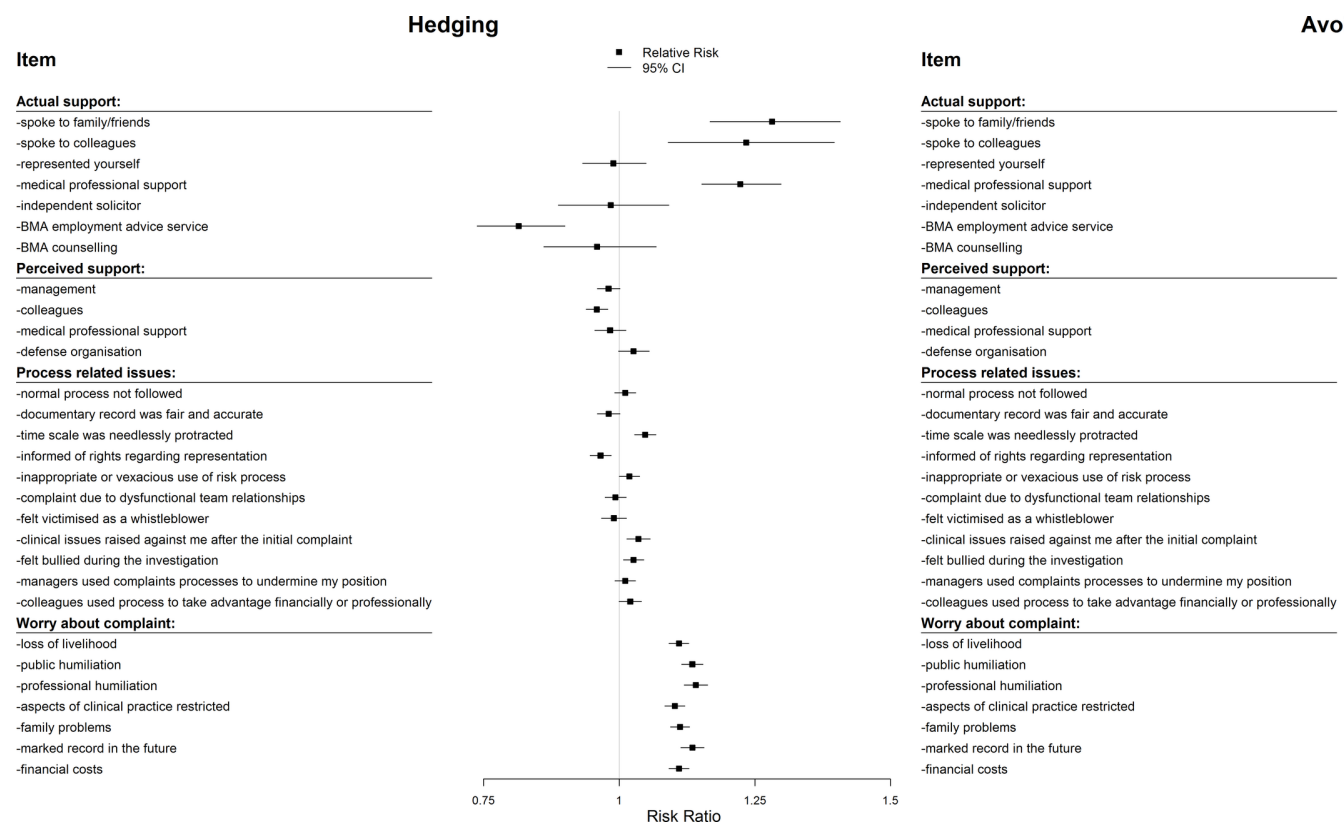

Avoidance

Item

Actual suppor:

dependent solicitor

in counselling

fense organisation

public humiliation

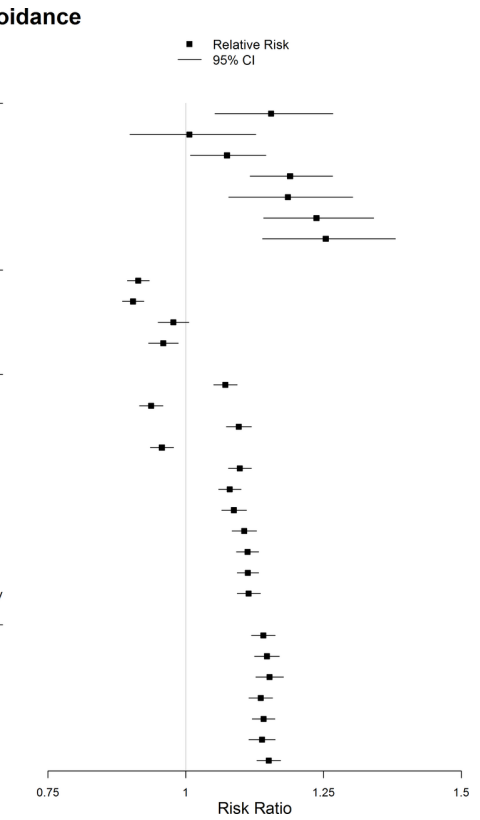

Figure 2 The relative risks (with 95\% Cls) for hedging and avoidance in relation to actual and perceived support as well as process-related issues.

well-informed about representation) were related to lower rates of avoidance.

Worrying about the consequences of the complaint was related to higher rates of hedging and avoidance (RRs: 1.10-1.14 for hedging and 1.14-1.15 for avoidance).

Interactions with type of complaint and recent/past complaint We have no evidence that relationships with the outcome variables depend on type or timing of complaint based on the dependent false discovery rate procedure. Details of these results are given in online supplementary file 2.

\section{DISCUSSION}

We have shown that there are a number of factors relating to complaints processes and how they are managed that are associated with the well-being of doctors involved as well as the likelihood of them practising defensive medicine. Our data suggest that how doctors respond to complaints is associated with their perception of the fairness of the process used to investigate them and the behaviour of colleagues involved. The RR of anxiety and depression was increased when doctors reported the timescale of a complaint was protracted, processes were not followed or used inappropriately and managers or colleagues used complaints processes to their advantage. Importantly, psychological morbidity increased when complaints were associated with a dysfunctional team, whistleblowing and bullying. Conversely, evidence of good process such as being kept well-informed and accurate minute taking was associated with improved psychological welfare and less defensive practice. Feeling supported by colleagues was associated with the greatest positive impact.

A strength of the study is that to our knowledge, this is the largest study relating to this subject in the UK with responses from over 6000 doctors. A further important factor is that we guaranteed that all responses would be anonymous and untraceable, which we think is vital when asking doctors for their opinions on issues that involve complaints processes and in particular their regulator. We believe it is important that we have used validated instruments to assess levels of anxiety and depression. The main limitation of the study is the overall response rate of $11.4 \%$, and so we must be cautious about the possibility of ascertainment bias. However, it should also be remembered that doctors who have been most traumatised may avoid taking part in the survey, while doctors who have been struck of the register, changed profession or committed suicide would not have completed the survey. A further consideration when interpreting the data, are that levels of support were self-reported by the doctors in the study. The study specifically relates to doctors and complaints processes in the UK, so our findings may not be generalisable in terms of other healthcare settings.

The results suggest there may be an association between speaking to family, friends and colleagues and accessing support from a professional organisation and increased hedging and avoidance. It seems more likely that these actions reflect a tendency to seek advice in cases where the impact is greatest. A similar pattern is seen for depression and anxiety. The clear exception is 'speaking with colleagues'. When doctors reported that they spoke to colleagues, they were significantly less likely to suffer from anxiety and depression, although it must be acknowledged that it is possible that doctors who are more anxious inherently find it more difficult to speak to colleagues. However in the event of a serious event, a doctor may be suspended from practice and denied the opportunity to access colleagues. Our data suggest 
this practice may damage the mental health of doctors and should be avoided. While removing a doctor from clinical contact to protect patients may be necessary, it is unreasonable to stop them asking colleagues for support. Indeed, it might be better if this was encouraged. It is notable that when doctors perceived they had the support of both colleagues and management, this was associated with less avoidance and psychological morbidity.

In 2012, McGivern et al ${ }^{18}$ described how values associated with 'transparency' such as openness, independent review and accountability, although generally assumed to be beneficial, may have unintended consequences. These authors also examined reactivity mechanisms using interviews with medical staff and concluded that clinicians make sense of regulation through the experiences of their peers and stated 'this heightens their anxiety about regulators misunderstanding the complexity of their practice and looking to find malpractice in an inquisition-like climate of presumed guilt'. ${ }^{18}$ We have previously described how approximately $80 \%$ of doctors report hedging (eg, overprescribing, over-referral) and 40\% report avoidance (abandoning procedures early, avoiding difficult patients or procedures). These behaviours may have a serious impact on patient care. Our data suggest there is an association between how investigations are carried out, the support given to doctors while being subject to investigation and both defensive practice and psychological morbidity. An example of this is the time taken to carry out a complaint investigation. Seventy-eight per cent of respondents indicated that the timescale involved in their complaint was protracted, while figures 1 and 2 show that a protracted timescale is associated with increased avoidance as well as anxiety and depression. More rigorous oversight of regulators and those tasked to investigate complaints locally with fixed timescales permitted for investigation and resolution of a complaints process would seem deliverable. It would also seem a straightforward requirement that investigative bodies follow normal processes, and documentation is fair. A summary box showing factors associated with positive and negative impact on doctors during complaints investigation is shown in online supplementary file 3 .

A further important factor appears to be the behaviour both of colleagues and those carrying out an investigation. Feeling undermined by management, feeling bullied or victimised, being involved in a dysfunctional team, inappropriate or vexatious use of clinical risk processes and feeling colleagues were taking advantage of the situation were associated with more depression, anxiety and avoidance. Bullying and undermining are unfortunately relatively common within the National Health Service in the UK. ${ }^{19}$ It should be possible to rectify these issues by ensuring those carrying out investigations are knowledgeable and follow clear, transparent processes. More widely, these issues require cultural change to be supported by national bodies. An example of this is the Royal College of Obstetricians and Gynaecologists undermining toolkit. ${ }^{20}$
A recent review of doctors who committed suicide while under investigation by the GMC concluded that the GMC has a demonstrable duty of care to those it investigates. ${ }^{21}$ The authors cited poor communication, lack of support and unacceptable delays as being factors that increased physician stress. These themes are not dissimilar to the procedural issues we found to be associated with increased psychological morbidity. Our data are derived from all complaints processes and not just referrals to the GMC, so this is a much wider problem than the almost 10000 doctors referred to the regulator in the UK. ${ }^{22}{ }^{23}$ Our findings were similar irrespective of the type of complaint. It would seem perceived and actual support, the use of appropriate process and the behaviour of colleagues is important irrespective of the type of investigation, and that all these may have a significant impact on the wellbeing of doctors. Even though more support may be in place for serious complaints such as to the GMC, a doctor's perception may be that support is inadequate in relation to the severity of the process being faced. The relative lack of assistance for low-level complaints may lead to similar perceptions of lack of support.

It is likely that complaints may lead to some positive changes in practice for some physicians, such as improved record keeping. However, it is noteworthy that in our previous qualitative report on this database only $6 \%$ of doctors described complaint investigations as a positive experience. ${ }^{2}$ Overwhelmingly the experience appears to be negative, and procedures that cause avoidance and hedging will be harmful to patients and incur significant costs. In the USA, a recent call to action in the American Journal of Obstetrics and Gynecology highlighted the dangers of burnout. ${ }^{24}$ The National Academy of Medicine has also recognised there is an urgent need to address the issue of physician wellbeing. ${ }^{25}$ As part of these initiatives, rectifying a culture for investigating complaints that damages doctors and potentially harms patients because of defensive practice should be a priority.

\section{Author affiliations}

${ }^{1}$ Department of Obstetrics and Gynaecology, Queen Charlotte's \& Chelsea Hospital, Imperial College London, London, UK

${ }^{2}$ Department of Obstetrics and Gynaecology, University Hospitals Leuven, Leuven, Belgium

${ }^{3}$ Department of Development and Regeneration, KU Leuven, Leuven, Belgium

${ }^{4}$ British Medical Association, London, UK

${ }^{5}$ LUCAS, KU Leuven, Leuven, Belgium

${ }^{6}$ South London and Maudsley NHS Foundation Trust, London, UK

Acknowledgements Christoph Lees (Imperial College NHS trust) and Magnus Boyd (Schillings International LLP) contributed to receiving feedback on the design and contents of the survey. The authors also thank the clinicians who commented on the initial versions of the survey.

Contributors TB conceived of the original idea for the study, interpreted results, drafted the paper and is overall guarantor. MJ designed the questionnaire, obtained ethical approval, contributed to the preparation of the data set, interpreted results and contributed to drafts of the paper. BDC, LW and BVC carried out the statistical analysis and contributed to interpretation of results and drafts of the papers. MP contributed to the study design, interpretation of results and commented on drafts of the paper. DT and CVA contributed to interpretation 
of results and commented on drafts of the paper. All authors approved the final version of the manuscript.

Funding LW holds a post-doctoral research mandate from Interne Fondsen KULeuven/Internal Funds KU Leuven.

Competing interests MP is head of the BMA doctors for doctors unit and so receives payment from the BMA.

Ethics approval King's College London, Psychiatry, Nursing and Midwifery Research Ethics Subcommittee (PNM/12/13-22).

Provenance and peer review Not commissioned; externally peer reviewed.

Data sharing statement № additional data available.

Open Access This is an Open Access article distributed in accordance with the Creative Commons Attribution Non Commercial (CC BY-NC 4.0) license, which permits others to distribute, remix, adapt, build upon this work non-commercially, and license their derivative works on different terms, provided the original work is properly cited and the use is non-commercial. See: http://creativecommons.org/ licenses/by-nc/4.0/

(C) Article author(s) (or their employer(s) unless otherwise stated in the text of the article) 2017. All rights reserved. No commercial use is permitted unless otherwise expressly granted.

\section{REFERENCES}

1. Bourne T, Wynants $L$, Peters $M$, et al. The impact of complaints procedures on the welfare, health and clinical practise of 7926 doctors in the UK: a cross-sectional survey. BMJ Open 2015:5:e006687.

2. Bourne T, Vanderhaegen J, Vranken R, et al. Doctors' experiences and their perception of the most stressful aspects of complaints processes in the UK: an analysis of qualitative survey data. BMJ Open 2016;6:e011711.

3. Verhoef LM, Weenink JW, Winters S, et al. The disciplined healthcare professional: a qualitative interview study on the impact of the disciplinary process and imposed measures in The Netherlands. BMJ Open 2015;5:e009275.

4. Jain A, Ogden J. General practitioners' experiences of patients' complaints: qualitative study. BMJ 1999;318:1596-9.

5. McGivern G, Fischer M. Medical regulation, spectacular transparency and the blame business. J Health Organ Manag 2010;24:597-610.

6. Reisch LM, Carney PA, Oster NV, et al. Medical malpractice concerns and defensive medicine: a nationwide survey of breast pathologists. Am J Clin Pathol 2015;144:916-22.

7. Studdert DM, Mello MM, Sage WM, et al. Defensive medicine among high-risk specialist physicians in a volatile malpractice environment. JAMA 2005;293:2609-17.
8. Bark P, Vincent C, Olivieri L, et al. Impact of litigation on senior clinicians: implications for risk management. Qual Health Care 1997;6:7-13.

9. Spitzer R, Kroenke K, Williams J. Validation and utility of a selfreport version of PRIME-MD: the PHQ Primary Care Study. JAMA 1999;282:1737-44

10. Kroenke K, Spitzer RL, Williams JB. The PHQ-9: validity of a brief depression severity measure. J Gen Intern Med 2001;16:606-13.

11. Spitzer RL, Kroenke K, Williams JB, et al. A brief measure for assessing generalized anxiety disorder: the GAD-7. Arch Intern Med 2006;166:1092-7.

12. Nash L, Walton M, Daly M, et al. GPs' concerns about medico legal issues: How it affects their practice. Australian Fam Physician 2009;38:66-70

13. Summerton N. Positive and negative factors in defensive medicine: a questionnaire study of general practitioners. BMJ 1995;310:27-9.

14. Zou G. A modified poisson regression approach to prospective studies with binary data. Am J Epidemiol 2004;159:702-6.

15. Benjamini Y, Yekateuli D. "The control of the false discovery rate in multiple testing under dependency". Annals of Statistics 2001;29:1165-88.

16. Buuren S, Groothuis-Oudshoorn K. Mice : multivariate imputation by chained equations in R. J Stat Softw 2011;45:1-67.

17. R Core Team. $R$ : A language and environment for statistical computing. $R$ foundation for statistical computing. Vienna, Austria 2015. http://www.R-project.org/

18. McGivern G, Fischer MD. Reactivity and reactions to regulatory transparency in medicine, psychotherapy and counselling. Soc Sci Med 2012;74:289-96.

19. Shabazz T, Parry-Smith W, Oates S, et al. Consultants as victims of bullying and undermining: a survey of Royal College of Obstetricians and Gynaecologists consultant experiences. BMJ Open 2016;6:e011462.

20. The RCOG/RCM undermining toolkit. https://www.rcog.org.uk/en/ careers-training/workplace-workforce-issues/improving-workplacebehaviours-dealing-with-undermining/undermining-toolkit/ (accessed 23 Sep 2017).

21. Casey D, Choong KA. Suicide whilst under GMC's fitness to practise investigation: Were those deaths preventable? J Forensic Leg Med 2016;37:22-7.

22. General Medical Council Fitness to Practice Annual Statistics Report 2014. 2017 http://www.gmc-uk.org/06 Fitness to Practise Annual_Statistics_Report_2014.pdf_61112494.pdf (accessed 28 Jan 2017).

23. Bourne T. Cutting GMC investigations must not simply devolve problems elsewhere. BMJ 2016;353:i2445.

24. Atallah F, McCalla S, Karakash S, et al. Please put on your own oxygen mask before assisting others: a call to arms to battle burnout. Am J Obstet Gynecol 2016;215:731.e1-731.e6.

25. National Academy of Medicine Action Collaborative on Clinician Well-Being and Resilience. 2017. https://nam.edu/initiatives/clinicianresilience-and-well-being/. 